Correction

Correction: Palombo, A. and Santini, F. ImaAtCor: A Physically Based Tool for Combined Atmospheric and Topographic Corrections of Remote Sensing Images. Remote Sensing 2020, 12, 2076

\author{
Angelo Palombo ${ }^{(D)}$ and Federico Santini *(D) \\ Italian National Research Council, Piazzale Aldo Moro, 7-00185 Roma, Italy; angelo.palombo@cnr.it \\ * Correspondence: federico.santini@cnr.it
}

Received: 27 August 2020; Accepted: 31 August 2020; Published: 3 September 2020

The authors wish to make the following corrections to this paper [1]: to replace any occurrence of ImaAtCor with ImaACor throughout the document (title, main body, Figure 1) due to the change of the name of the software.

The authors would like to apologize for any inconvenience caused to the readers by these changes.

\title{
1. Change in Title
}

We ask to replace ImaAtCor with ImaACor in the title of this article which was recently published in Remote Sensing. [1]:

The correct title should be: ImaACor: A Physically Based Tool for Combined Atmospheric and Topographic Corrections of Remote Sensing Images.

\section{Change in Main Body Paragraphs}

The authors are sorry to report that the name of the software shown in their recently published paper [1] was changed due to a conflict with some DLR trademarks. Consequently, the authors wish to make at this time the following corrections to the paper: to replace all occurrences of ImaAtCor with ImaACor throughout the paper.

\section{Change in Figures}

The authors wish to replace the Figure 1 of this paper [1].

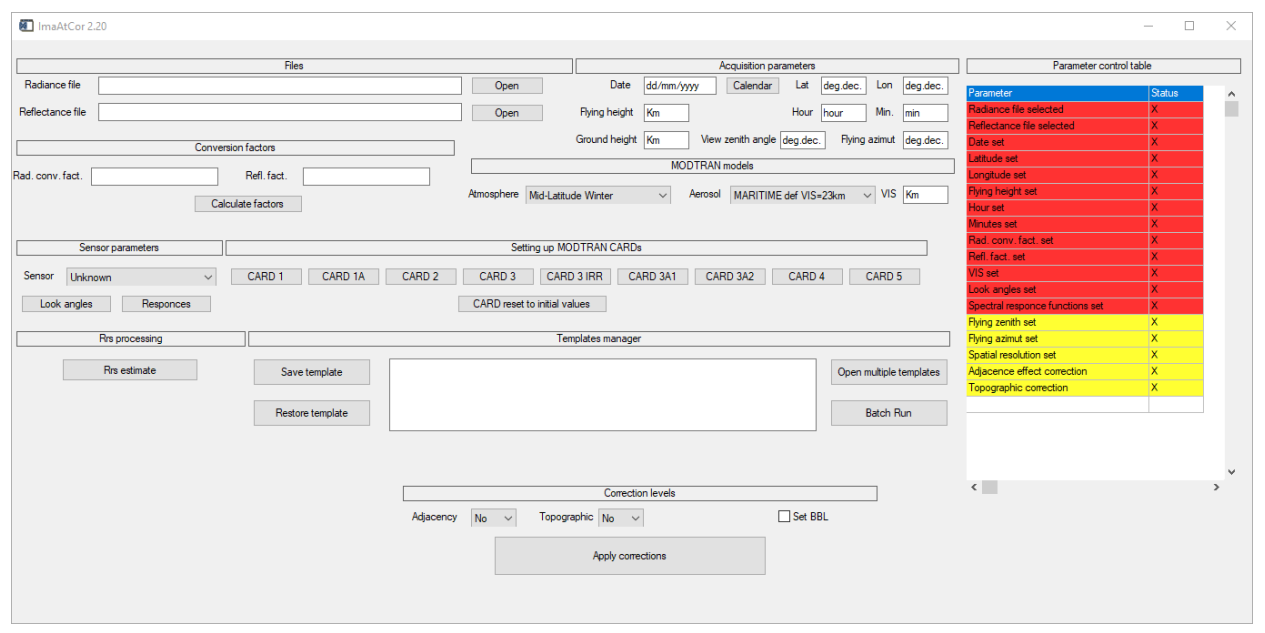

with 


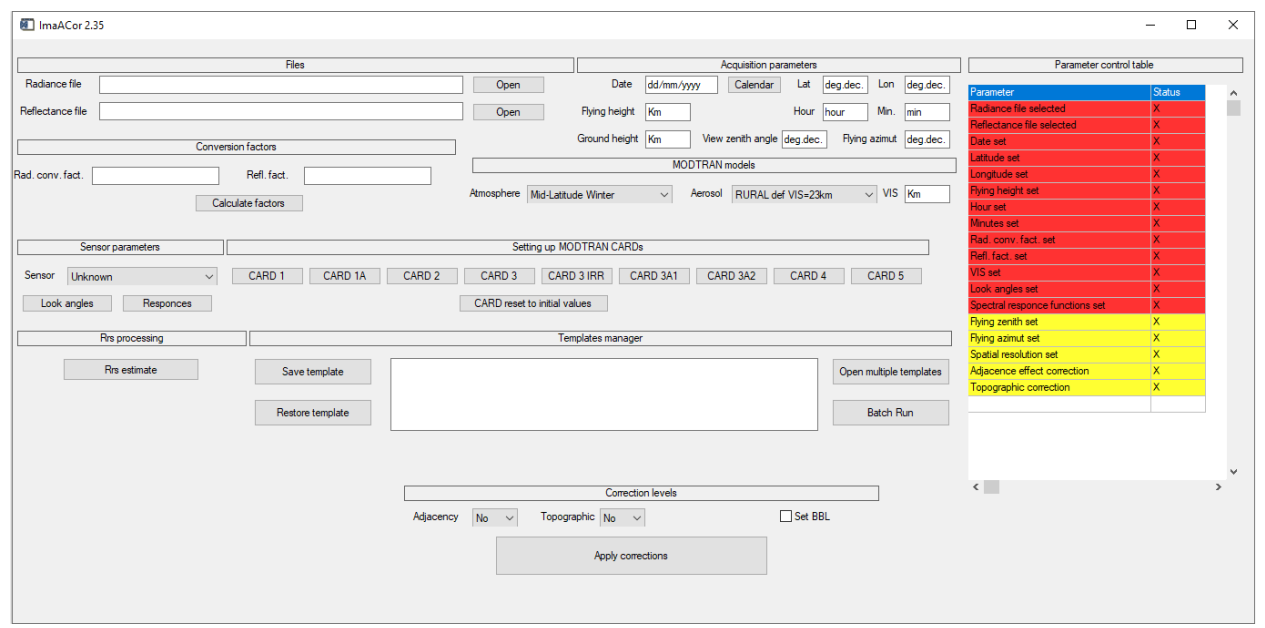

\section{Reference}

1. Palombo, A.; Santini, F. ImaAtCor: A Physically Based Tool for Combined Atmospheric and Topographic Corrections of Remote Sensing Images. Remote Sens. 2020, 12, 2076. [CrossRef] article distributed under the terms and conditions of the Creative Commons Attribution (CC BY) license (http://creativecommons.org/licenses/by/4.0/). 